\title{
miR-25 enhances cell migration and invasion in non-small-cell lung cancer cells via ERK signaling pathway by inhibiting KLF4
}

\author{
XIAOLI DING ${ }^{1}$, TIANYU ZHONG ${ }^{1}$, LIXIA JIANG ${ }^{1}$, JUNYUN HUANG $^{1}$, YU XIA $^{2}$ and RONG HU ${ }^{1}$ \\ ${ }^{1}$ Department of Laboratory Medicine, First Affiliated Hospital of Gannan Medical University; \\ ${ }^{2}$ Graduate Student Major of Laboratory Medicine of Gannan Medical University, Ganzhou, Jiangxi 341000, P.R. China
}

Received May 2, 2017; Accepted December 8, 2017

DOI: $10.3892 / \mathrm{mmr} .2018 .8772$

\begin{abstract}
In recent years, microRNAs (miRNAs/miRs) have gained increasing interest in cancer research. Increasing evidences demonstrated that miRNAs are important for tumor early detection and prognosis. The present study aimed to explore the function of miR-25 in non-small-cell lung cancer (NSCLC) and its underlying mechanisms. The expression levels of miR-25 and Krüppel-like factor 4 (KLF4) were assessed in 31 pairs of tissue from patients with NSCLC. In addition, the biological roles of miR-25 in NSCLC were analyzed via a cell wound healing assay, Transwell invasion and migration assays. Target genes of miR-25 were predicted using TargetScan and verified via a dual luciferase activity assay, western blotting and reverse transcription-quantitative polymerase chain reaction. The downstream signaling pathway was confirmed by western blot analysis. In the present study, miR-25 was overexpressed in 31 NSCLC samples compared with in corresponding normal tissues. Overexpression of miR-25 using miR-25 mimics markedly promoted NSCLC cell migration and invasion, while inhibition of miR-25 exerted the opposite effect. KLF4 was suggested to be a novel target gene of miR-25 in NSCLC cells. Knockdown of KLF4 promoted the migration and invasion of NSCLC cells, whereas rescue of KLF4 expression reduced cell motion ability in miR-25-overexpressing NSCLC cells. Furthermore, it was demonstrated that miR-25 activated the extracellular signal-regulated kinase (ERK) signaling pathway, which eventually led to increased vimentin, matrix metalloproteinase 11 and $\mathrm{N}$-cadherin levels, and the downregulation of E-cadherin expression by inhibiting the expression of KLF4. In conclusion, miR-25 was demonstrated to activate the ERK signaling pathway by directly targeting KLF4, promoting cell migration and invasion. The
\end{abstract}

Correspondence to: Professor Rong Hu, Department of Laboratory Medicine, First Affiliated Hospital of Gannan Medical University, 23 Qingnian Road, Ganzhou, Jiangxi 341000, P.R. China

E-mail: 13607979088@163.com

Key words: microRNA-25, Krüppel-like factor 4, migration, invasion, extracellular signal-regulated kinase signaling pathway, non-small-cell lung cancer findings of the present study indicated that miR-25 or KLF4 may serve as a therapeutic target for the treatment of NSCLC.

\section{Introduction}

Primary lung cancer is the leading cause of global cancer morbidity and cancer-associated mortality, accounting for $\sim 1.59$ million cases of mortality annually $(1,2)$. Among lung cancer types, $>85 \%$ of cases are presently identified as non-small cell lung cancer (NSCLC) (3). The treatment of patients diagnosed with lung cancer has significantly improved due to medical advances; however, the prognosis for NSCLC is remains poor and the 5-year overall survival rate is only $15 \%$ (4). The poor prognosis of patients with NSCLC is closely associated with distant metastasis. Consequently, further investigation is required to understand the potential mechanisms of metastasis in NSCLC.

Krüppel-like factors (KLFs) belong to the evolutionary conserved family of zinc finger transcription factors in mammals (5). KLF4, one of the earliest identified genes in the KLF family, is widely detected in a variety of human tissues and is reported to be crucial for diverse physiological processes, including development, differentiation and apoptosis, and stemness in embryonic stem cells (6). KLF4 is a bifunctional molecule displaying dual functions in different human cancers depending on the intracellular environment or the cell type. KLF4 can act as an oncogene, and it was previously reported that the expression levels of KLF4 were elevated in breast cancer and squamous cell carcinoma $(7,8)$; whereas, in esophageal, human colon and gastric cancer, KLF4 served as a tumor suppressor (9-11). Research focusing on the effect of KLF4 in tumorigenesis has increased in recent years; however, the underlying mechanism of KLF4 in tumorigenesis is not clear. MicroRNAs (miRNAs) are single-stranded, non-coding RNA molecules of 18-22 nucleotides that can cause translational inhibition and/or mRNA degradation by binding to the 3' untranslated region (UTR) of target mRNAs (12). It has been estimated that miRNAs regulate the expression of a third of human genes (13). miRNAs are involved in the regulation of diverse biological processes, including invasion, migration, proliferation and cell apoptosis (14-16). Abnormal expression of miRNAs, including the upregulation of miR-429 (17), miR-19a (18) and miR-146a (19), and downregulation of miR-143 (20), miR-3666 (21) and miR-29b (22) have been 
detected in lung cancer. Thus, miRNAs have potential as biomarker for diagnosis, targeted therapy and prognosis.

miR-25 is one of the miR-106b-25 cluster (miR-93, miR-25 and miR-106b) $(23,24)$. Evidence has highlighted the key regulatory roles of miR-25 in tumor progression. For instance, $\mathrm{Su}$ et al (25) reported that upregulated miR-25 in liver cancer tissues led to a shorter survival time. Li et al (26) also reported that overexpressed miR-25 increased the proliferation, invasion and migration of gastric cancer cells by inducing the degradation of transducer of ERBB2 1 and also demonstrated that serum concentrations of miR-25 were positively associated with poor prognosis in patients with gastric cancer. However, in certain diseases, miR-25 was downregulated. For instance, diminished expression of miR-25 in colorectal cancer induced an increase in expression of angiopoietin like 2 and resulted in reduced cell clones, inhibited invasion and migration (27). Furthermore, Wu et al (28) studied miR-25, which was reported to promote cell growth and inhibit apoptosis in NSCLC by reducing modulator of apoptosis 1 expression. Xiang et al (29) revealed that miR-25 was overexpressed in NSCLC cells and tissues, and promoted the motility and proliferation of NSCLC cells, in part by diminishing F-box and WD repeat domain containing 7 expression levels. The majority of studies have investigated the biological function of miR-25 in lung cancer, however the underlying mechanism is remains unknown. The aim of the present study was to research the function of miR-25 in NSCLC and to improve the understanding of the underlying mechanism of miR-25 in NSCLC.

In the present study, the expression levels of miR-25 were examined in NSCLC tissues via reverse transcriptionquantitative polymerase chain reaction ( $R T-q P C R$ ). Subsequently, in vitro assays, including cell migration and invasion assays, were conducted to understand the biological functions of miR-25 in NSCLC. Additionally, KLF4 was demonstrated to be a novel target gene of miR-25, and to be involved in the invasion and migration in NSCLC cells Finally, the phosphorylation of extracellular signal-regulated kinase (ERK1/2; p44/42 mitogen-activated protein kinase) demonstrated that the ERK signaling pathway was downstream of miR-25. Collectively, the results of the present study revealed that miR-25 promoted the migration and invasion of NSCLC cells via regulation of the ERK1/2 signaling pathway by targeting KLF4.

\section{Materials and methods}

Tissue samples and cell lines. Pairs of normal and NSCLC tissue specimens $(n=31 ; 21$ male and 10 female; age, 41-77) were obtained from patients that received surgery at the Cardiovascular Surgery of First Affiliated Hospital of Gannan Medical University (Ganzhou, China) between January 2014 and March 2016. Specimens were placed immediately into liquid nitrogen following collection and were then stored at $-80^{\circ} \mathrm{C}$ until use. Written informed consent was obtained from the patients involved in the present study, which was approved by the Ethics Committee of Gannan Medical University. Human A549 and Calu1 NSCLC cell lines, GES-1 and 293T cells used in the present study were obtained from the Institute of Biochemistry and Cell Biology of the Chinese Academy of Sciences (Shanghai, China), A549, GES-1 and 293T cells were cultured in Dulbecco's modified Eagle's medium (DMEM), Calu1 cells were cultured in McCOYs 5A (HyClone; GE Healthcare Life Sciences, Logan, UT, USA). The culture medium was supplemented with $1 \%$ penicillin and streptomycin (HyClone; GE Healthcare Life Sciences), and 10\% fetal bovine serum (FBS; Gibco; Thermo Fisher Scientific, Inc., Waltham, MA, USA). The cells were cultivated in a humidified environment at $37^{\circ} \mathrm{C}$ with $5 \% \mathrm{CO}_{2}$.

$R T-q P C R$. Total RNA was extracted from the cultured cells and NSCLC tissues with TRIzol reagent (Invitrogen; Thermo Fisher Scientific, Inc.) according to the manufacturer's protocols. RNA was dissolved in diethylpyrocarbonate water. RT of mRNA and miRNA was conducted using ReverTra Ace ${ }^{\circledR}$ qPCR RT kit (Toyobo Life Science, Osaka, Japan) and miRNA reverse transcription kit (Promega Corporation, Madison, WI, USA). cDNA was subsequently harvested and qPCR was conducted with SYBR ${ }^{\circledR}$ Fast qPCR Mix (Takara Biotechnology Co., Ltd., Dalian, China) using a 7500 Fast Real-Time PCR detection system (Thermo Fisher Scientific, Inc.). qPCR reaction conditions were as follows: $95^{\circ} \mathrm{C}$ pre-denaturation for $3 \mathrm{~min}$, followed by 40 cycles of denaturing at $95^{\circ} \mathrm{C}$ for $3 \mathrm{sec}$, annealing and synthesis at $60^{\circ} \mathrm{C}$ for $30 \mathrm{sec}$; the $\mathrm{Cq}$ value was then determined. The primers for RT-qPCR was as follows: miR-25 forward, 5'-GCAGCATTGCACTTGTCTCG-3' and reverse, 5'-AGTGCAGGGTCCGAGGTATTC-3'; and KLF4 forward, 5'-AAGCCAAAGAGGGGAAGACG-3' and reverse, 5'-GTGCCTGGTCAGTTCATCTGAG-3'. The 18S and U6 were taken as internal control for KLF4 and miR-25 respectively. To calculate the expression levels of miR-25 and KLF4, the $2^{-\Delta \Delta \mathrm{Cq}}$ method was used (30). Overexpression was defined as a $\geq 1.5$-fold change and underexpression as a $\leq 0.67$-fold change, based on a previous study (31). All experiments were repeated three times independently.

Bioinformatics analysis. To identify the targets of miR-25 that may regulate the migration and invasion of NSCLC, the target prediction tool TargetScan version 7.1 (http://www.targetscan.org/mmu_71/) was used for target prediction of miR-25. The Database for Annotation, Visualization and Integrated Discovery (version 6.7; https://david.ncifcrf.gov) is a functional annotation tool that provides a comprehensive set of biological annotations to understand the meaning underlying a large list of target genes. The Gene Ontology (GO) (version 4.0; http://www.geneontology.org/) and Kyoto Encyclopedia of Genes and Genomes (KEGG; http://www. genome.jp/kegg/pathway.html) databases were used for functional clustering analysis and pathway location.

Vector construction. The primers on the flanks of the coding sequences of KLF4 were: Forward, ATACTCGAG ATGAGGCAGCCACCTGGC (Xhol) and reverse, CCA CTAGTTTAAAAATGCCTCTTCATGTGTAAG (SpeI). Primers were designed using Primer3 (version 4.1.0; http://primer3.ut.ee) according to the reference sequence in the University of California Santa Cruz Genome Browser (https://genome.ucsc.edu). The KLF4 cDNA reverse transcribed from mRNA of GES-1 was used as a template. For the KLF4 vector, KLF4 cDNA was cloned into the pCMV-N-Flag plasmid (Beyotime Institute of Biotechnology, 
Shanghai, China) between $\mathrm{XhoI}$ and SpeI restriction sites to construct the KLF4 overexpression plasmid. For the 3'-UTR of the KLF4 vector, the primers for the 3'-UTR of KLF4 containing the putative binding site of miR-25 was amplified by PCR. The primers for the 3'-UTR of KLF4 sequence were: Forward, 5'-GGTCTCGAGGGATATGACCCACACTGCC-3' (XholI) and reverse, 3'-TTAAGCGGCCGCCCTTGAGTA TGCAAAATACAAACTCC-5' (NOTI). and cloned into the psi-CHECK2 vector (Promega Corporation) using the restriction endonucleases XholI and NotI. The insertion regions were sequenced by Biosune (Platinum Shang Biotechnology, Shanghai, China) to ensure the accuracy of each base.

Cell transfection. miR-25 mimics/inhibitors and its negative control (NC) miRNAs (mimic-NC/inhibitor-NC, respectively), siRNA and its negative control (si-NC) were purchased from Guangzhou RiboBio Co., Ltd. (Guangzhou, China). NC miRNAs of 20-30 base pairs served as the negative control and exhibited minimal effect on cells in the present study. miR-25 mimics are chemically synthesized, double-stranded RNAs which mimic mature endogenous miR-25 following transfection into cells. miR-25 inhibitors are chemically synthesized, single-stranded modified RNAs that specifically inhibit endogenous miRNA function following transfection into cells. Cells were transfected with $50 \mathrm{nM}$ miR-25 mimic (sense, 5'-CAUUGCACUUGUCUCGGUCUGA-3' and antisense, 3'-GUAACGUGAACAGAGCCAGACU-5'), inhibitor (5'-UCAGACCGAGACAAGUGCAAUG-3'), mimic-NC (sequence unavailable), inhibitor-NC (sequence unavailable), small interfering (si)RNA (hs-KLF4-si forward, 5'-GAG UCAUCUUGUGAGUGGAdTdT-3' and reverse, 5'-UCC ACUCACAAGAUGACUCdTdT-3') targeting KLF, or si-NC (sequence unavailable) with $3 \mu$ l Lipofectamine ${ }^{\circledR} 2000$ transfection reagent (Invitrogen; Thermo Fisher Scientific, Inc.). Plasmid transfection was conducted using $2 \mu \mathrm{g}$ KLF4 overexpression plasmid or KLF4-3'UTR plasmid with $4 \mu 1$ Lipofectamine ${ }^{\circledR} 2000$ according to the manufacturer's protocols.

Luciferase reporter assay. 293T cells transfected with miR-25/miR-NC mimics and wild type (WT)/mutated (MUT) psi-CHECK2-KLF4-3'UTR were transferred into 24-well plates and cultured until $90 \%$ confluence was reached. Luciferase activity was detected using the Dual-Luciferase ${ }^{\circledR}$ Reporter Assay System kit (cat. no. E1910; Promega Corporation). After $48 \mathrm{~h}$ post-transfection, cells were collected, centrifuged at $56,669 \times \mathrm{g}$ for $1 \mathrm{~min}$ at $4^{\circ} \mathrm{C}$ and lysed with passive lysis buffer (Promega Corporation). Culture plates were placed on a rocking platform for $15 \mathrm{~min}$ to ensure complete and even coverage of the cell monolayer with PLB. Cell lysates were transferred to a tube, and lysate samples were centrifuged for $30 \mathrm{sec}$ at $56,669 \mathrm{x}$ g at $4^{\circ} \mathrm{C}$. Cell lysate (20 $\mu \mathrm{l})$ was transferred into the luminometer tube containing Luciferase Assay Reagent II and was mixed by pipetting two or three times. Stop \& Glo ${ }^{\circledR}(100 \mu \mathrm{l})$ Reagent was added to the tube which was vortexed briefly to mix. The relative luciferase activity was subsequently detected with a microplate reader (Synergy 2; BioTek China, Beijing, China). The ratio of the Renilla fluorescence value to the firefly fluorescence value was calculated.
Wound healing assay. Cells were transfected with miR-25 inhibitor, mimic, KLF4 siRNA, KLF4 overexpression plasmid, miR-25 inhibitor NC (in-NC), miR-25 mimic NC (miR-NC), si-NC or empty vector. The ability of cell migration was evaluated via a wound healing assay. Calu1 and A549 cells were seeded into a 6-well plate (Corning Incorporated, Corning, $\mathrm{NY}$, USA) at a density of $1.8 \times 10^{5}$ cells $/ \mathrm{ml}$ and cultured, then transferred to 12 -well plate $24 \mathrm{~h}$ post-transfection and permitted to grow to a density of $90 \%$. Cells were scratched with a sterile yellow pipette tip and then washed several times with PBS to remove non-adherent cells. Leica Image Analysis (Leica Microsystem, Inc., Buffalo Grove, IL, USA) was used to capture images; gaps were measured using ImageJ software (version 1.51t; National Institutes of Health, Bethesda, MD, USA) to calculate healing percentages.

Transwell assay. Matrigel was pre-cooled and diluted 1:3 in medium without FBS, $50 \mu \mathrm{l}$ was added to the upper chamber and placed in the incubator for $1 \mathrm{~h}$. The cells were suspended with the culture medium containing $0.1 \%$ bovine serum albumin (BSA; Beyotime Institute of Biotechnology) at a density of $5 \times 10^{5} / \mathrm{ml}$, and $200 \mu \mathrm{l}$ was added in the upper chamber. A total of $500 \mu \mathrm{l}$ DMEM or McCOYs 5A medium containing 15\% FBS was added to the lower chamber. The culture plates were removed from the incubator following incubation for 24 or $48 \mathrm{~h}$ at $5 \% \mathrm{CO}_{2}$ and $37^{\circ} \mathrm{C}$. The cells from the upper layer of the chamber's filter membrane were cleared, and the chamber was washed with PBS, then placed into $95 \%$ ethanol to fix the cells adhering on the undersurface of filter membrane at room temperature for $10 \mathrm{~min}$, cells were then stained with $0.5 \%$ crystal violet $(2 \mathrm{mg} / \mathrm{ml}$; Sigma-Aldrich; Merck KGaA, Darmstadt, Germany) at room temperature for $30 \mathrm{~min}$. The number of cells was counted in five fields that were randomly selected under a light microscope, the average number of cells was recorded and analyzed.

Western blotting. Total proteins were harvested from transfected cells at $48 \mathrm{~h}$ after transfection and lysed using a mixture of radioimmunoprecipitation assay buffer (Beyotime Institute of Biotechnology), phenylmethane sulfonyl fluoride (Beyotime Institute of Biotechnology) and protease inhibitor cocktail (Roche Applied Science, Penzberg, Germany). The protein amount was determined using a bicinchoninic acid assay kit (Beyotime Institute of Biotechnology); $30 \mu \mathrm{g}$ total protein was used for western blotting. Different sized proteins were separated by the $10 \%$ SDS gel, then electrotransferred to polyvinylidene fluoride membranes (Merck $\mathrm{KGaA})$. BSA (2-5\%) was applied to the membranes, which were incubated at room temperature for $1 \mathrm{~h}$ to remove nonspecific binding. Subsequently, the membranes were incubated with the following primary antibodies overnight at $4^{\circ} \mathrm{C}(1: 1,000)$ : Matrix metalloproteinase 11 (MMP11; cat. no. ab201757; Abcam, Cambridge, UK); E-cadherin (cat. no. ab1416; Abcam); KLF4 (cat. no. 043474; CST Biological Reagents Co., Ltd., Shanghai, China); phosphorylated (p)-ERK1/2 (cat. no. 4370S; CST Biological Reagents Co., Ltd.); ERK1/2 (cat. no. 4695P; CST Biological Reagents Co., Ltd.); N-cadherin (cat. no. 4061p; CST Biological Reagents Co., Ltd.); vimentin (cat. no. 12826; Cell Signaling Technology, Inc., Danvers, MA, USA); anti- $\beta$-actin antibody (1:5,000; cat. no. sc-47778; Santa Cruz Biotechnology, Inc., 
Dallas, TX, USA) and the membrane was incubated. The membranes was washed three times with PBS with Tween-20 to remove the unbound primary antibody, then incubated with the secondary antibodies of corresponding species for $1 \mathrm{~h}$ [1:5,000, anti-rabbit (cat. no. BS13278; Biogot Technology Co., Ltd., Nanjing, China) or anti-mouse (cat. no. BS10043; Biogot Technology Co., Ltd.)] at $37^{\circ} \mathrm{C}$ for $1 \mathrm{~h}$. Protein bands were scanned and visualized under automated chemiluminescence image analysis system (Tanon 5200; Tanon Science and Technology Co., Ltd., Shanghai, China) following incubation with an enhanced chemiluminescent substrate (Thermo Fisher Scientific, Inc.) for $2 \mathrm{~min}$. $\beta$-actin served as the internal control.

Statistical analysis. The data of the present study are presented as the mean \pm standard deviation from three independent experiments and analyzed with version 21.0 of SPSS (IBM Corp., Armonk, NY, USA). The difference between two groups was analyzed by Student's t-test. One-way analysis of variance was to compare multiple groups followed by Tukey's post hoc test. $\mathrm{P}<0.05$ was considered to indicate a statistically significant difference.

\section{Results}

miR-25 is overexpressed in NSCLC tissues. miR-25 expression levels were analyzed in NSCLC tissues and matched normal tissue by RT-qPCR. Overexpression was defined as a $>1.5$ fold increase and underexpression a $<0.67$ fold decrease. Analysis demonstrated that 25 of the 31 tissues exhibited miR-25 overexpression compared with in corresponding normal tissues $(\mathrm{P}<0.05$; Fig. 1).

miR-25 regulates invasion and migration of NSCLC cells. To research the function of miR-25 in migration and invasion in NSCLC cells, A549 and Calu1 cells were transfected with miR-25 mimics, inhibitor or the negative controls. The transfection efficiency was detected by RT-qPCR (Fig. 2). Results of wound healing assays showed that miR-25 inhibition reduced cell migration compared with control cells, leading to larger scratch areas than control cells (Fig. 3A and B). Cell motility was then assessed via Transwell migration and invasion assays, which indicated that miR-25 inhibition effectively repressed the invasion and migration of NSCLC cells (Fig. 3C and D). By contrast, the scratch gap in the miR-25 overexpression group was smaller than the NC group (Fig. 4A and B), and in the Transwell assays, the number of cells crossing through the membrane was increased by miR-25 mimics compared the NC group (Fig. 4C and D). These results indicated that the inhibition of miR-25 weakened NSCLC cell motility, while overexpression of miR-25 exhibited opposite effects.

Identification of KLF4 as an endogenous target gene of miR-25 in NSCLC cells. GO analysis of miR-25 targets demonstrated that the molecular function of the target genes was predominantly concentrated in 'protein binding' (Fig. 5A). In addition, KEGG functional annotation of the target genes in cancer pathways is presented in Fig. 5B. In comprehensive consideration of functional targets and literature reports, KLF4 was eventually identified as a potential target gene of miR-25 (Fig. 6A) and further verified by a dual luciferase assay and western blotting. It was observed that overexpression of miR-25 significantly inhibited the relative luciferase value of psi-CHECK2-KLF4-3'UTR-WT; however, it did not alter psi-CHECK2-KLF4-3'UTR-MUT (Fig. 6B). Western blot analysis demonstrated that the miR-25 inhibition promoted KLF4 protein expression, whereas the miR-25 mimics reduced KLF4 protein expression levels (Fig. 6C and D). In addition, RT-qPCR revealed that 28 of 31 pairs of lung cancer tissues exhibited a decrease in KLF4 expression levels (Fig. 6E and F), indicating that KLF4 expression was decreased in NSCLC tissues compared with adjacent control tissues. These data suggested that KLF4 may be a target gene of miR-25.

Knockdown of KLF4 increases invasion and migration of NSCLC cells. In order to investigate the biological function of KLF4, KLF4 expression was inhibited by transfection with siRNA (Fig. 7A-C). A wound healing assay demonstrated that knockdown of KLF4 accelerated the migration of cells compared with the control groups (Fig. 7D and E). The results of the migration and invasion assays were consistent with those of the wound healing assay (Fig. 7F and G), which suggested that the effects of KLF4 knockdown were similar to those of miR-25 overexpression.

Migration and invasion-promoting effects of miR-25 are partially attenuated by KLF4 overexpression. To further investigate whether KLF4 upregulation may attenuate the oncogenic effects of miR-25 on NCSLC cells, the pCMV-N-flag-KLF4 plasmid was transfected into miR-25-overexpressing A549 and Calu1 cells (Fig. 8A and B). Wound healing assays (Fig. 8C and D) and Transwell invasion and migration assays (Fig. 8E and F) demonstrated that the exogenous supplementation of KLF4 may weaken the oncogenic function of miR-25 in NSCLC cells. The results of the present study suggested that miR-25 promoted NSCLC cell migration and invasion by inhibiting KLF4 expression.

miR-25 promotes cells invasion and migration via the ERK signaling pathway. To clarify the mechanism of miR-25 in regulating cell motility, the downstream signaling pathways of miR-25 were investigated. Considering that KLF4 inhibited the role of miR-25 in suppressing NSCLC cell invasion and migration, and KLF4 is involved in the ERK signaling pathway, this suggests that miR-25 may regulate the ERK1/2 pathway by inhibiting the expression of KLF4. As presented in Fig. 9, the level of p-ERK1/2 and the markers of invasion and metastasis (vimentin, N-cadherin and MMP11) were reduced, and expression of E-cadherin was increased by miR-25 inhibition. Consistent with these findings, the overexpression of miR-25 in NSCLC cells activated the ERK1/2 signaling pathway, which was reversed by overexpression of KLF4 via co-transfection with pCMV-N-flag-KLF4. The findings of the present study demonstrated that miR-25, which inhibited KLF4 expression, promoted cell invasion and migration by activating the ERK signaling pathway.

\section{Discussion}

NSCLC, the most common lung cancer type, is studied by researchers worldwide. As invasion and metastasis facilitate 

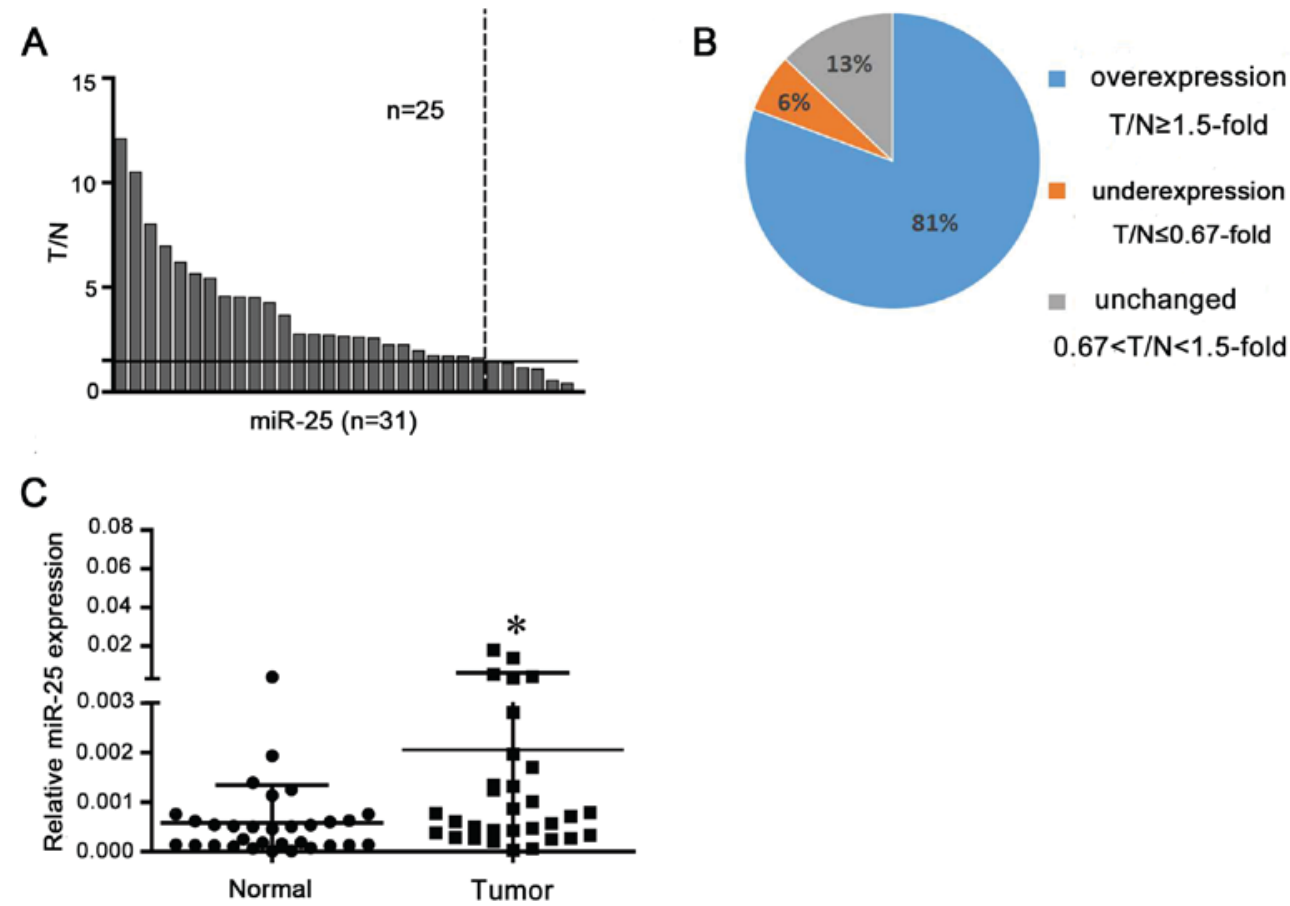

Figure 1. miR-25 is overexpressed in NSCLC tissues. (A) Relative expression levels of miR-25 in tumor and normal tissues were measured by RT-qPCR in 31 pairs of human NSCLC samples and their corresponding normal tissues ( $\mathrm{n}=31$ pairs). The relative expression of miR-25 in each tissue was calculated using the $2^{-\triangle \Delta C q}$ method and U6 acted as the endogenous reference gene. In each pair of clinical samples, the expression of miR-25 in the tumor tissues were referenced to corresponding normal tissues. The settings presented in the figure was as follows: The graph was divided into high expression and low expression sections by black solid lines of $\mathrm{T} / \mathrm{N}=1.5$. The expression of miR-25 in 25 pairs cancerous tissue samples was $\geq 1.5$ fold higher than that in adjacent tissues (left side of the black dashed line); the remaining 6 pairs of samples (right side of black dashed line) had $\mathrm{T} / \mathrm{N}<1.5$-fold. (B) Distribution of miR-25 expression in 31 pairs clinical specimens, which was divided into three sections by using $\mathrm{T} / \mathrm{N} \geq 1.5$ and $\mathrm{T} / \mathrm{N} \leq 0.67$ in the pie chart. (C) Relative expression levels of miR-25 were measured by RT-qPCR in 31 pairs non-small-cell lung cancer tissues and adjacent normal tissues samples. Data are presented as the mean \pm standard deviation from three independent experiments. " $\mathrm{P}<0.05$. miR, microRNA; RT-qPCR, reverse transcription-quantitative polymerase chain reaction; $\mathrm{T} / \mathrm{N}$, tumor/normal.

A

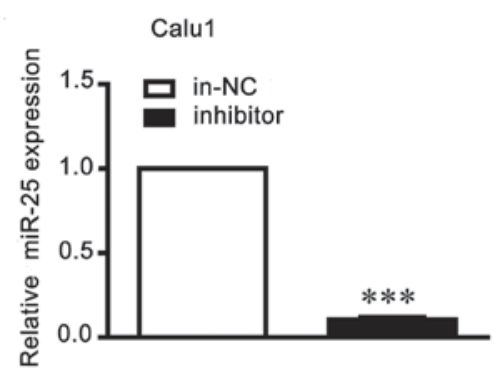

C

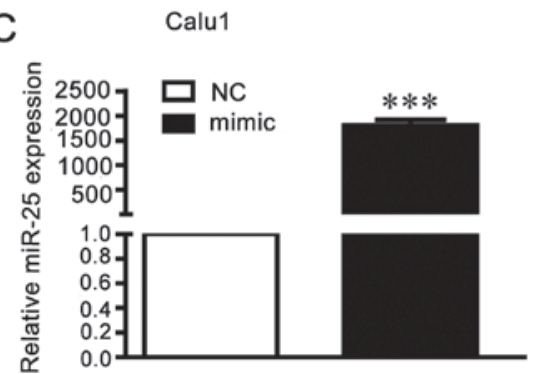

B

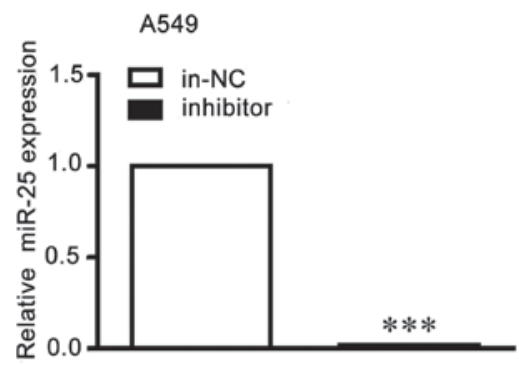

D

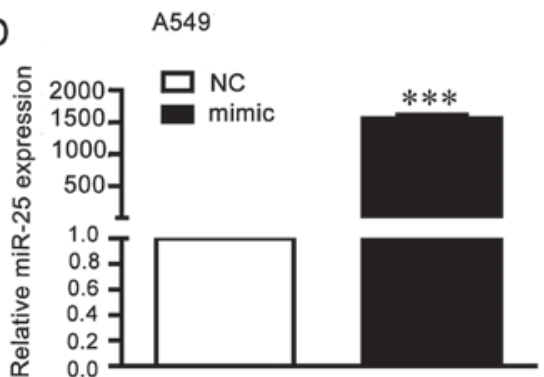

Figure 2. miR-25 regulates invasion and migration of pairs non-small-cell lung cancer cells. Transfection efficiencies of inhibitor in (A) Calu1 and (B) A549 cells. Transfection efficiencies of mimics in (C) Calu1 and (D) A549 cells. ${ }^{* * * *} \mathrm{P}<0.001$. miR, microRNA; in-NC, inhibitor negative control; NC, mimic negative control.

NSCLC progression, it is important to further clarify the mechanisms of pathogenesis and metastasis of NSCLC.

The results of the present study indicated that miR-25 promoted the invasion and migration of NSCLC cells via the ERK1/2 signaling pathway by targeting KLF4. In the present study, the detailed experiments revealed that miR-25 was upregulated within NSCLC tumor tissue samples compared with in the corresponding paracancerous tissues 
A
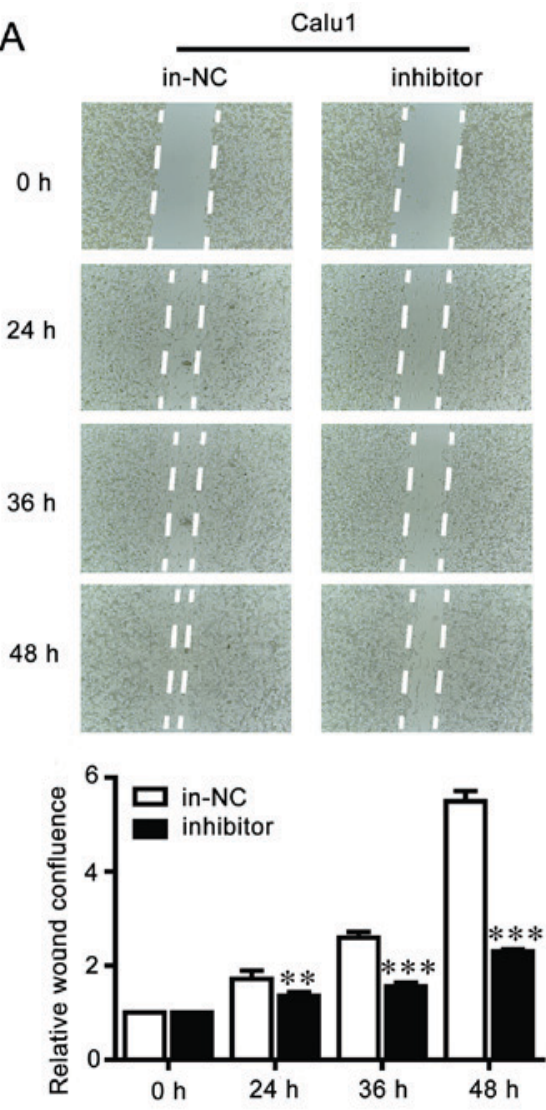

Calu1
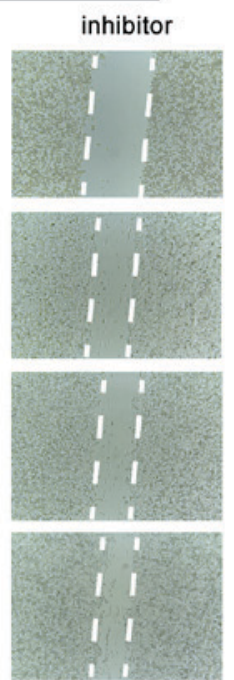

11
C
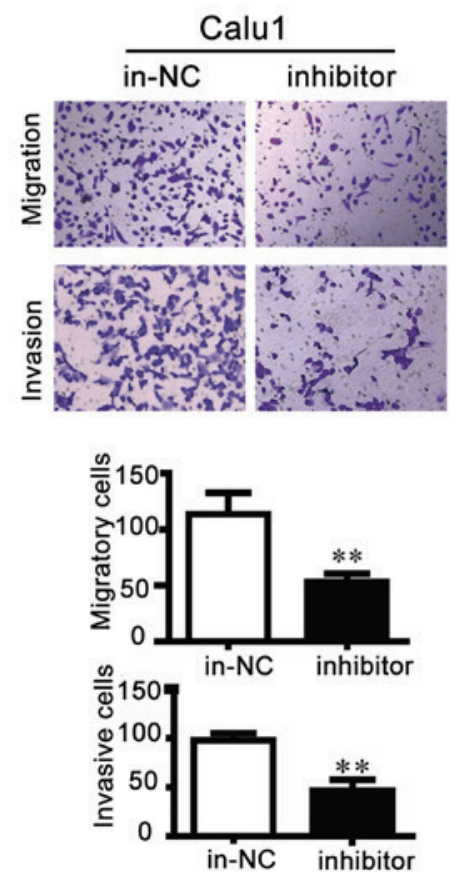

B
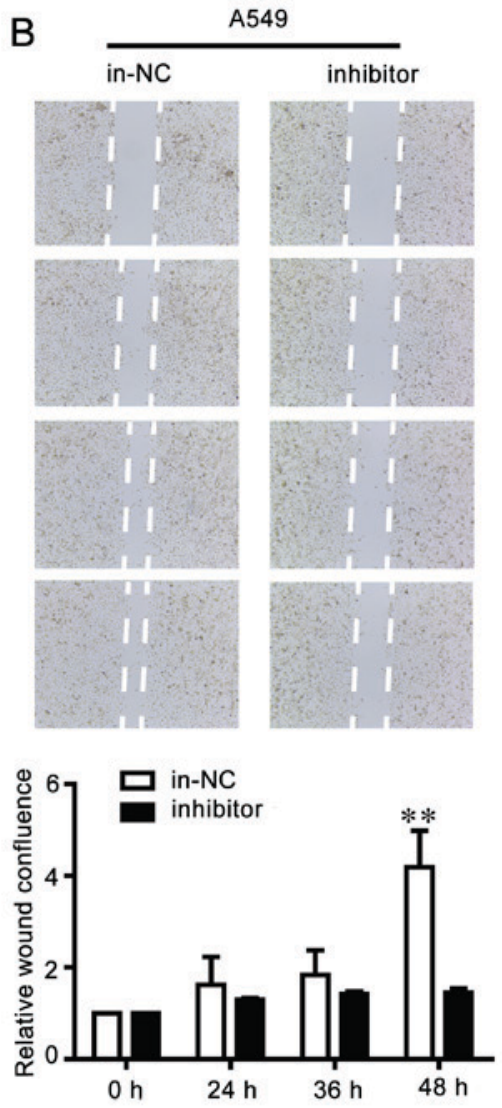

D $\frac{\mathrm{A} 549}{\text { in-NC inhibitor }}$
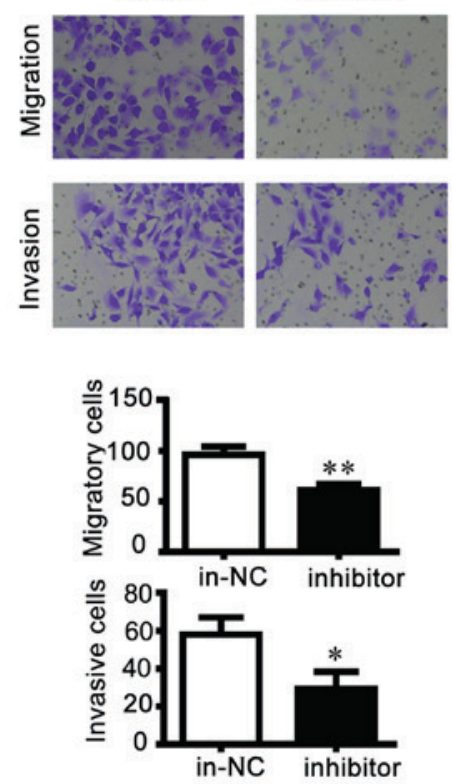

Figure 3. MicroRNA-25 inhibition reduces invasion and migration of non-small-cell lung cancer cells. (A) Calu1 and (B) A549 cells in culture for migration assay were monitored at various time points. The image of the wound gap was captured at 0, 24, 36 and $48 \mathrm{~h}$ (magnification, x 50). Quantitative wound confluence data of cell lines. Transwell migration and invasion assays in (C) Calu1 and (D) A549 cells were employed to analyze cell migration and invasive abilities (magnification, $\mathrm{x} 200$; crystal violet staining). ${ }^{*} \mathrm{P}<0.05,{ }^{* *} \mathrm{P}<0.01,{ }^{* * *} \mathrm{P}<0.001$ vs. in-NC. in-NC, inhibitor negative control.

by RT-qPCR analysis. Downregulation of miR-25 using miR inhibitor repressed the migration and invasion of NSCLC cells. By contrast, overexpression of miR-25 by transfection with miR-25 mimic accelerated the motility of NSCLC cells in vitro. The results of the present study suggested that miR-25 promoted the invasion and migration of NSCLC cells.

In addition, using the prediction software, TargetScan 7.1, KLF4 was identified as a potential target of miR-25, which was verified by luciferase reporter assay and western blot 
A

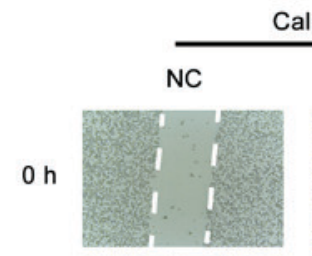

$24 \mathrm{~h}$

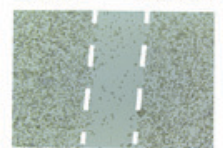

$36 \mathrm{~h}$

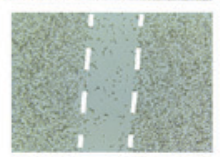

$48 \mathrm{~h}$
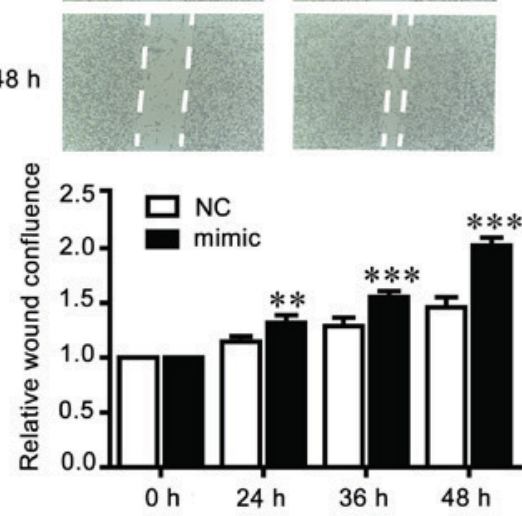

C
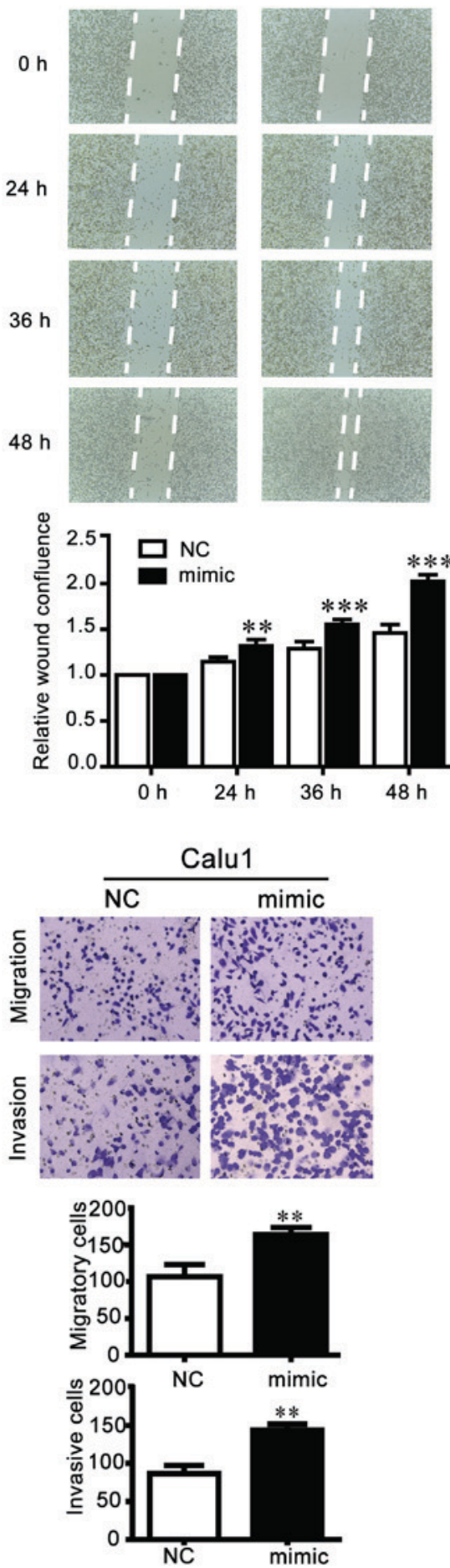

B
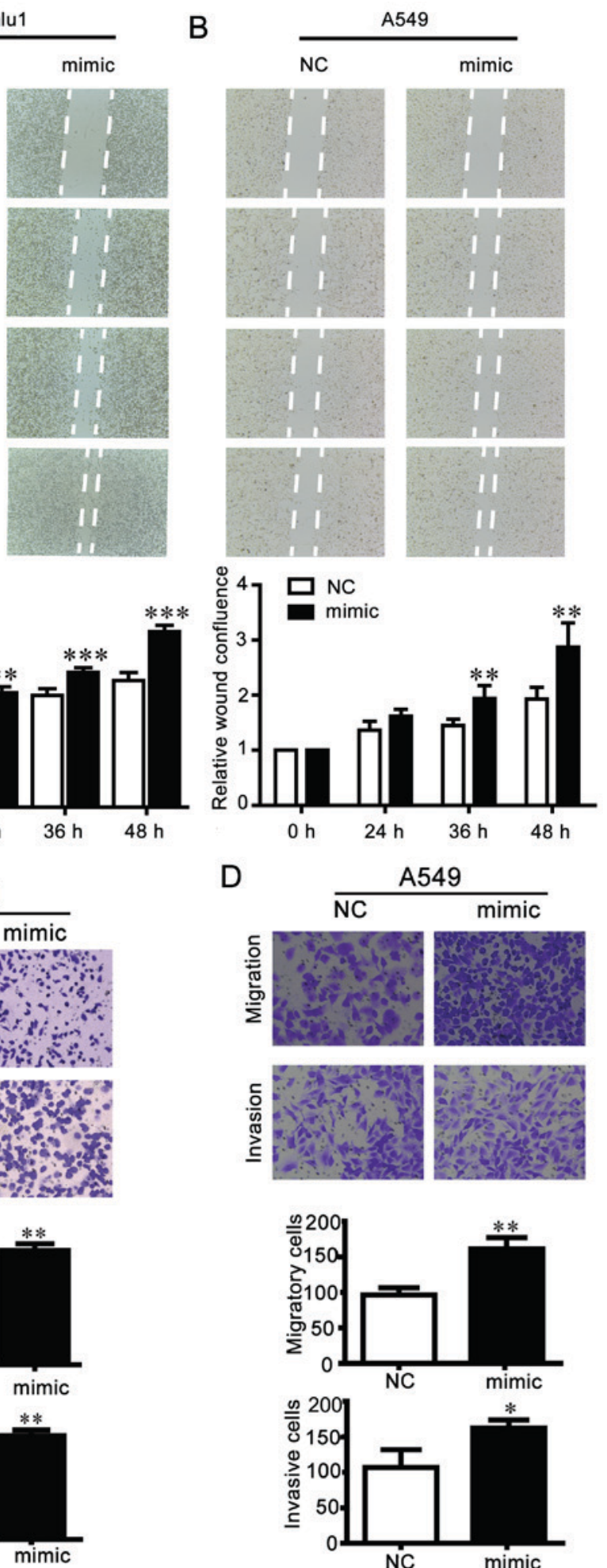

Figure 4. MicroRNA-25 mimics increase invasion and migration of non-small-cell lung cancer cells. (A) Calu1 and (B) A549 cells in culture for migration assay were monitored at various time points. The image of the wound gap was captured at 0, 24, 36 and $48 \mathrm{~h}$ (magnification, x50). Quantitative wound confluence data of cell lines. Transwell migration and invasion assays in (C) Calu1 and (D) A549 cells were employed to analyze cell migration and invasive abilities (magnification, $\mathrm{x} 200$; crystal violet staining). ${ }^{*} \mathrm{P}<0.05,{ }^{* *} \mathrm{P}<0.01,{ }^{* * *} \mathrm{P}<0.001$ vs. NC. NC, mimic negative control.

analysis. Subsequently, the clinical expression of miR-25 and KLF4 was investigated. Previous studies have reported the role of KLF4 on inducible senescence in the process of the generation of induced pluripotent stem cells (32-34). $\mathrm{Xu}$ et al (35) clarified that cell senescence may be promoted by KLF4 via the miR-203-survivin-p21 pathway. Studies have indicated that KLF4 may act as an anti-oncogene in lung cancer $(36,37)$. Exogenous KLF4 may reduce the colony formation and viability ability of cells in in vitro assays. Additionally, overexpressing KLF4 in lung cancer cells also inhibits tumor proliferation in vivo (38). The findings of the present study demonstrated that the knockdown of KLF4 

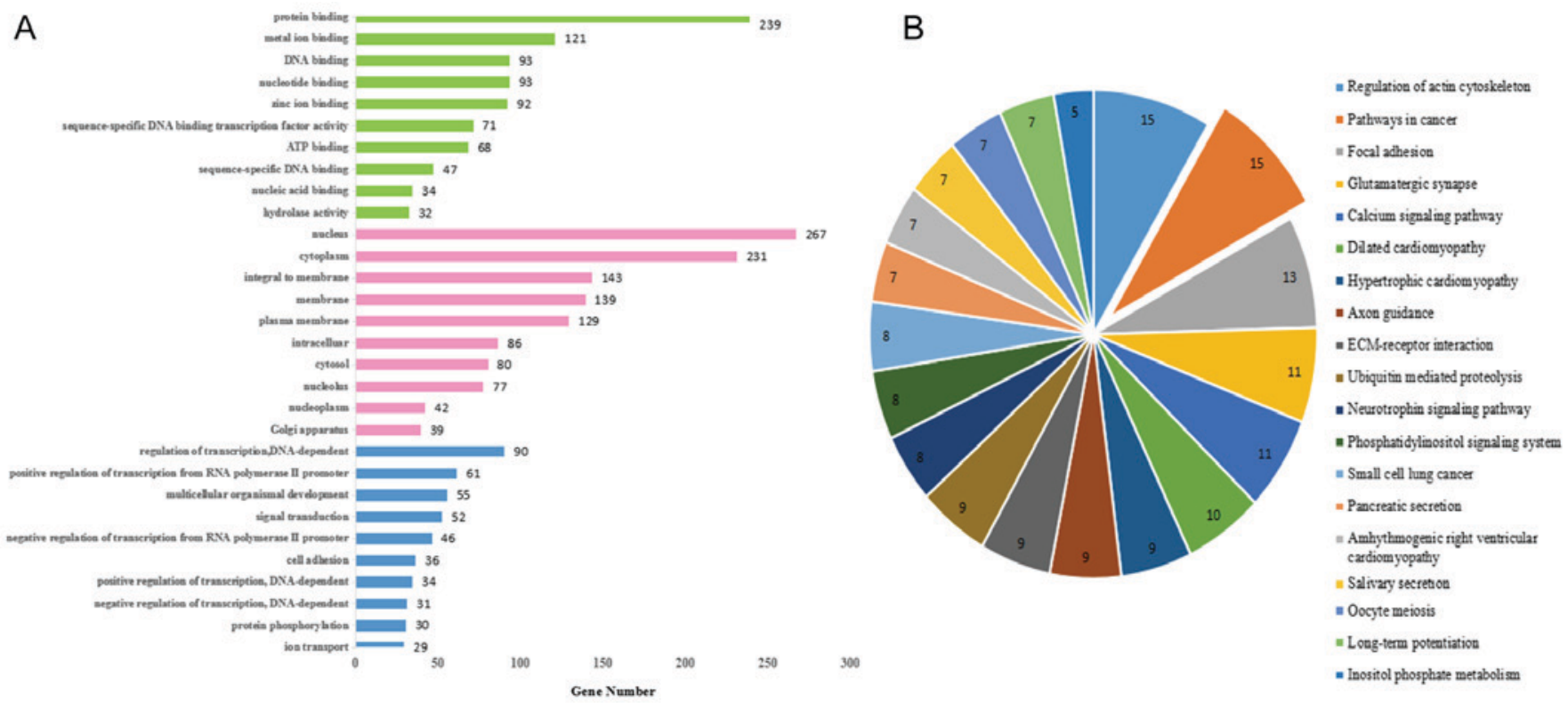

Figure 5. Functional annotation of the target genes of microRNA-25. (A) Gene Ontology function of the target genes. (B) Kyoto Encyclopedia of Genes and Genomes functional annotation of the target genes. ECM, extracellular matrix.

A

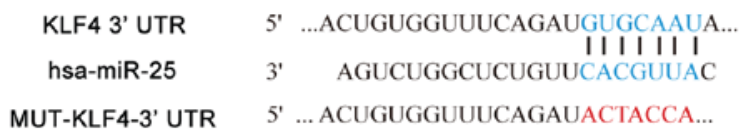

B

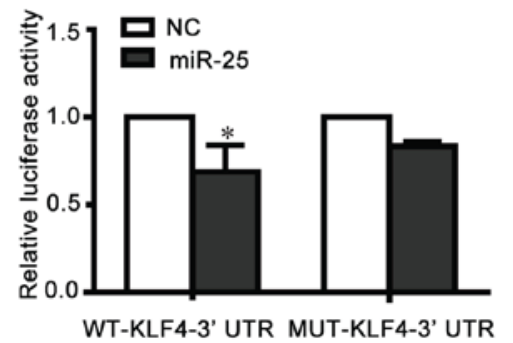

$\mathrm{E}$

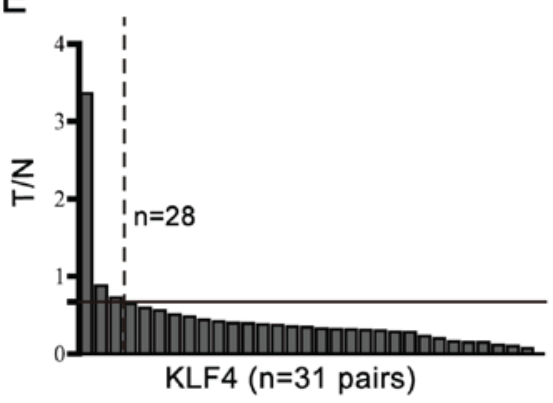

C
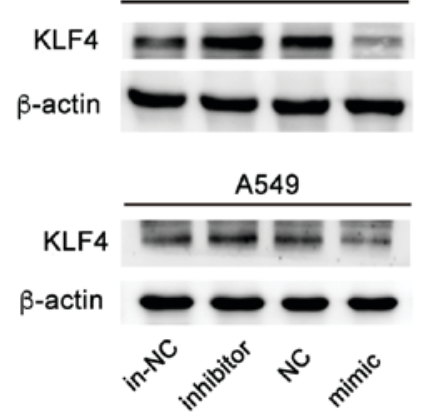

$\mathrm{F}$
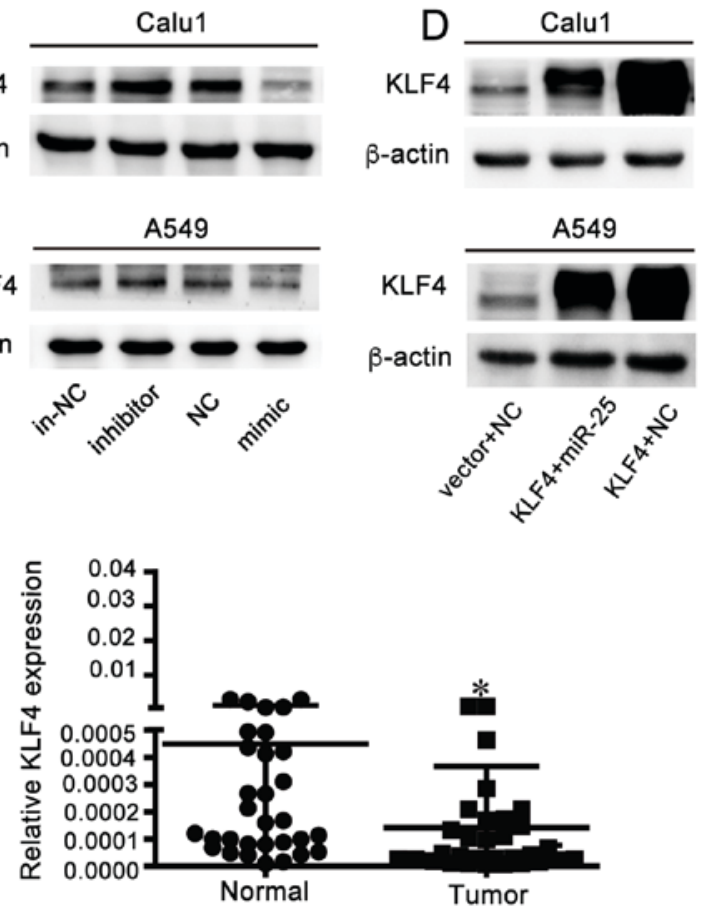

Figure 6. Identification of KLF4 as an endogenous target gene of miR-25 in NSCLC cells. (A) Wild-type or mutant psi-CHECK2-KLF4-3'-UTR vector sequence and the binding site (blue sequence) between wild-type KLF4-3'-UTR and miR-25 and wild-type mutation location (red sequence) were presented. (B) 293T cells transfected with luciferase vectors containing wide type or mutant KLF4-3'-UTR and NC or miR-25, respectively were used for the luciferase assay. Luciferase activity was normalized to firefly luciferase activity. "P<0.05 vs. NC. Western blotting analysis demonstrated expression KLF4 post-transfection with (C) miR-25 mimic/inhibitor or (D) co-transfection of miR-25 and KLF4. (E) Relative expression alterations of KLF4 (T/N) were measured by RT-qPCR in 31 pairs of human NSCLC samples and their corresponding control tissues. The relative expression levels of KLF4 in each tissue were calculated using the $2^{-\triangle \Delta C q}$ method using $18 \mathrm{~S}$ as the endogenous reference gene. In each pair of clinical samples, the expression of KLF4 in the tumor tissues (T) was referenced to corresponding normal tissues $(\mathrm{N})$. The settings presented in the figure were as follows: The graph is divided into high expression and low expression sections by black solid lines of $\mathrm{T} / \mathrm{N}=0.67$. The expression of KLF4 in 28 pairs cancerous tissues samples 0.67 -fold lower than in adjacent tissues (right of the black dashed line, $\mathrm{T} / \mathrm{N}<0.67$-fold), and the remaining 3 pairs of samples (left of black dashed lines) with $\mathrm{T} / \mathrm{N}>0.67$-fold. (F) Relative expression levels of KLF4 in 31 pairs NSCLC tissues and adjacent normal tissues samples measured by RT-qPCR and using $18 \mathrm{~S}$ as reference genes. " $\mathrm{P}<0.05$ vs. normal. RT-qPCR, reverse transcription-quantitative polymerase chain reaction; NSCLC, non-small-cell lung cancer; KLF4, Krüppel-like factor 4; UTR, untranslated region; MUT, mutated; $\mathrm{NC}$, negative control; miR, microRNA; in-NC, inhibitor negative control; T/N, tumor/normal. 
A

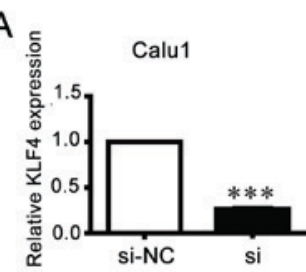

$\mathrm{B}_{\text {与 }}$<smiles></smiles>
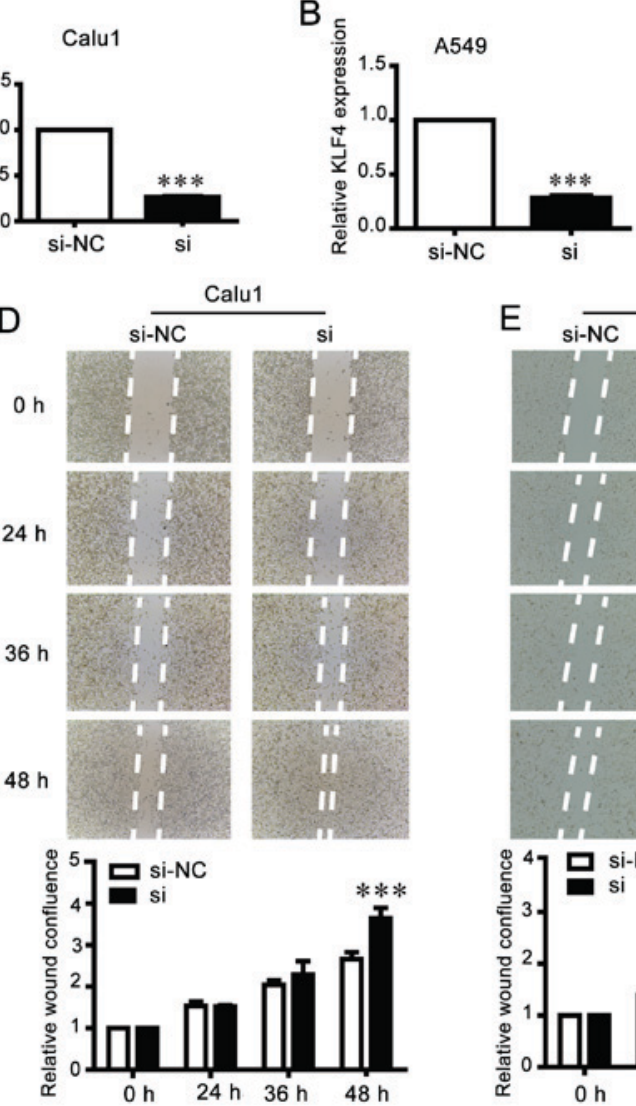

C

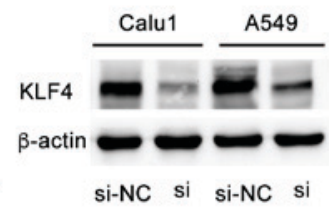

E
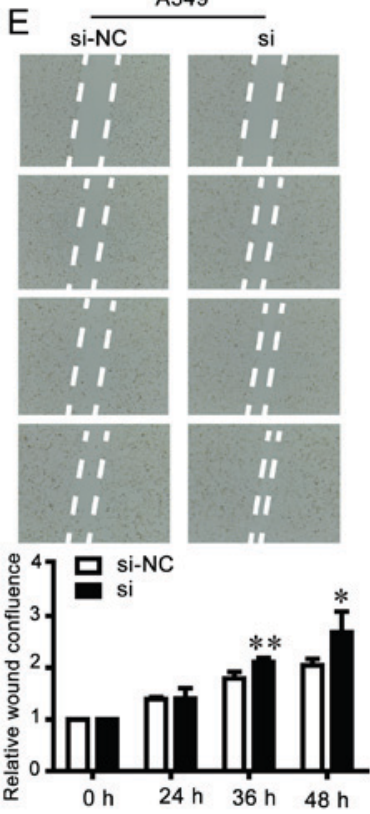

F
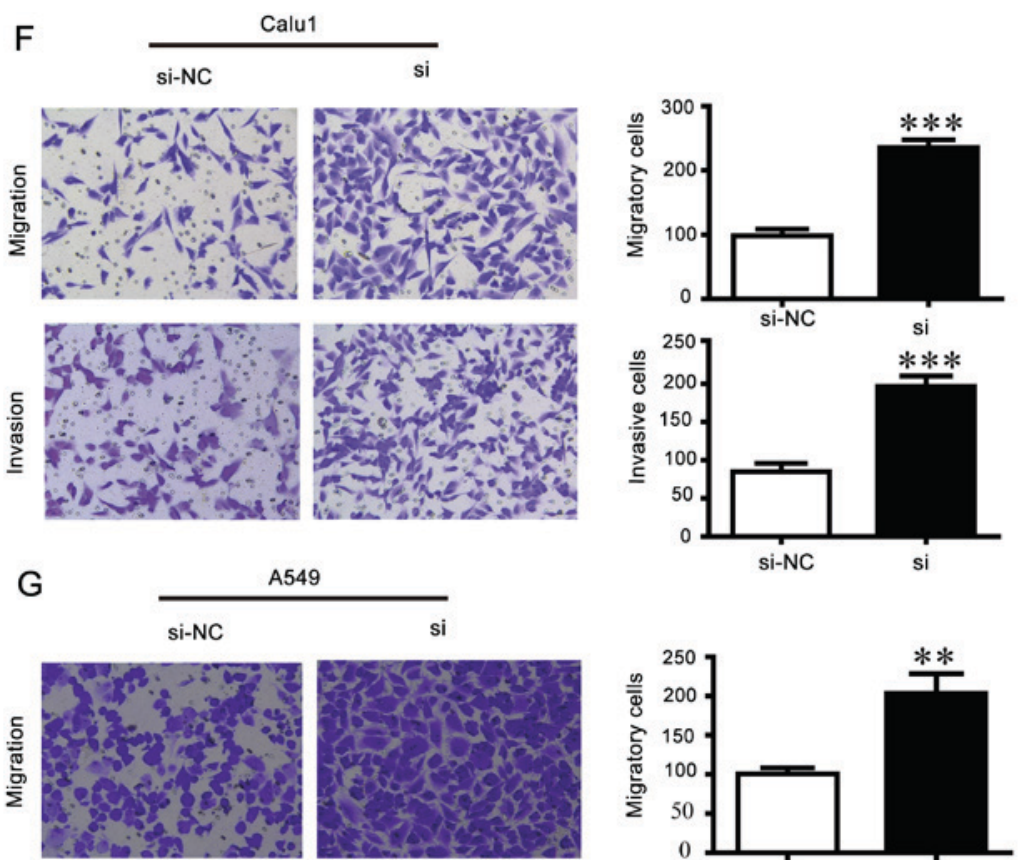

A549
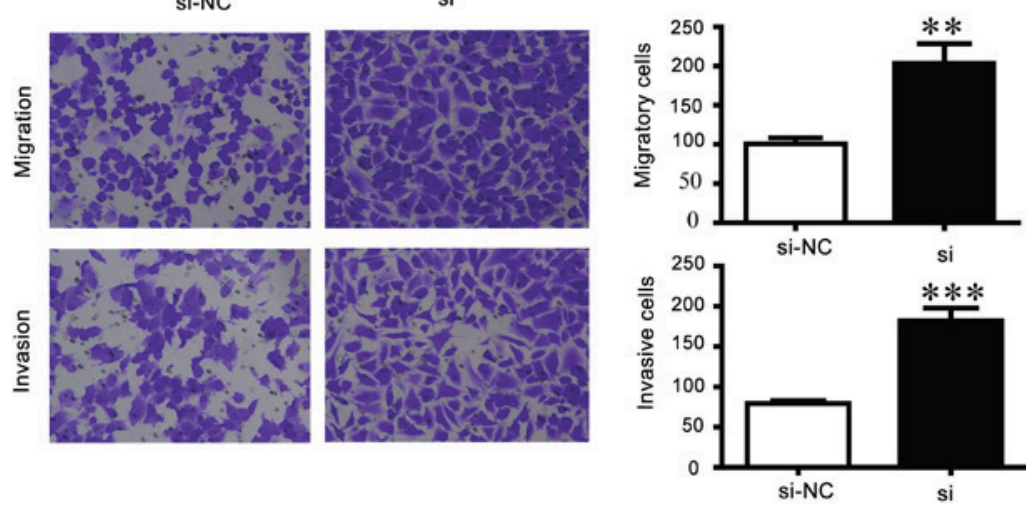

Figure 7. Knockdown of KLF4 increases non-small-cell lung cancer cells invasion and migration ability. KLF4 mRNA levels were measured in (A) Calu1 and (B) A549 cells transiently transfected with si-KLF4 or si-NC, and (C) protein expression levels of KLF4 are were determined by western blotting. Wound healing assays in (D) Calu1 and (E) A549 cells transfected with si and NC (magnification, x50). Quantitative data of gap closure was measured. (F) Calu1 and (G) A549 cells were transfected with si or si-NC, and migratory and invasive cells were detected in Transwell assays (magnification, $\mathrm{x} 200$; crystal violet staining). ${ }^{*} \mathrm{P}<0.05,{ }^{* *} \mathrm{P}<0.01,{ }^{* * *} \mathrm{P}<0.001$. KLF4, Krüppel-like factor 4; si, KLF4 small interfering RNA; si-NC, siRNA negative control. 
A

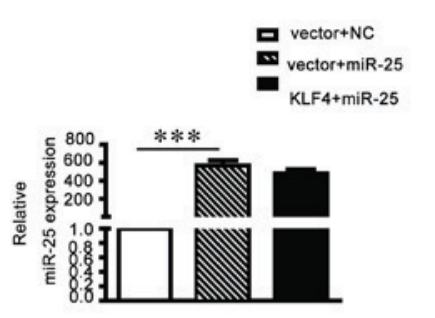

C
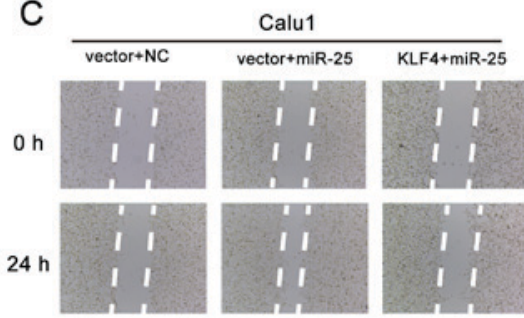

$36 \mathrm{~h}$
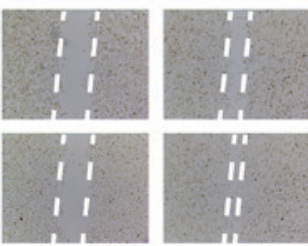

$48 \mathrm{~h}$
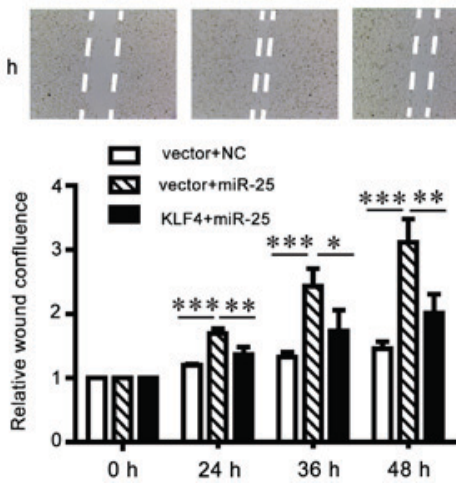

E
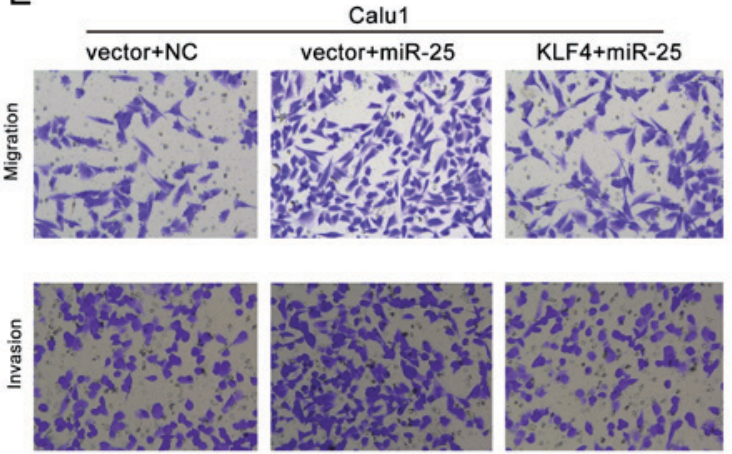

$\mathrm{F}$
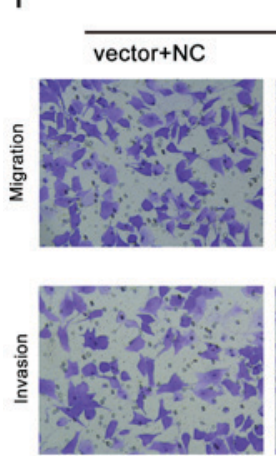

B
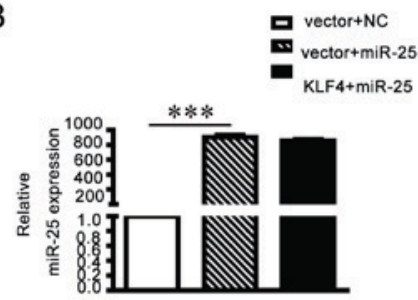

D
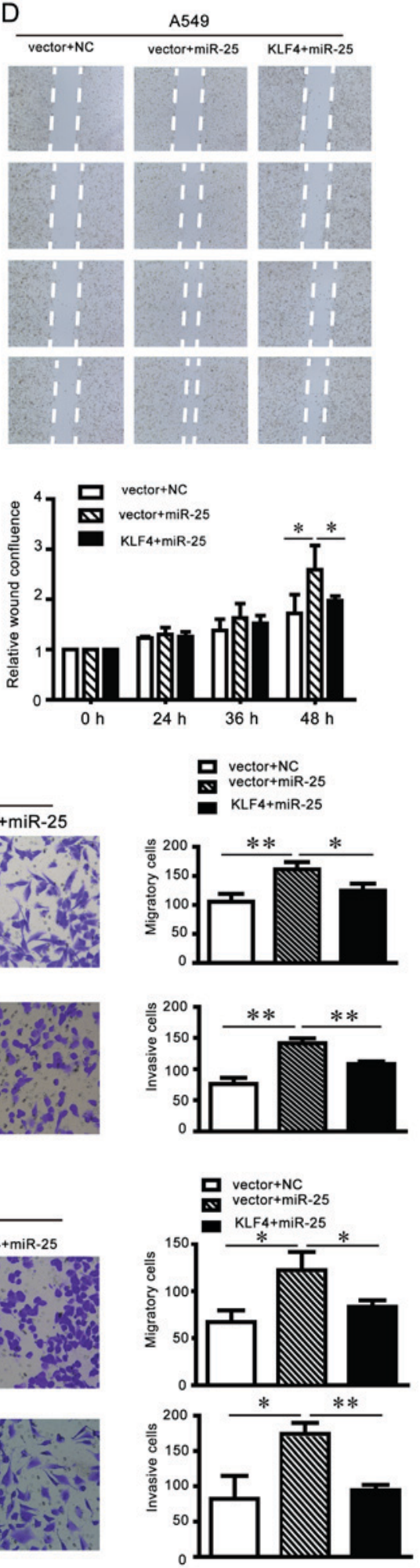

Figure 8. Migration and invasion promoting-effects of miR-25 are attenuated partially by KLF4 overexpression. Transfection efficiency was verified in (A) Calu1 and (B) A549 cells by reverse transcription-quantitative polymerase chain reaction analysis in cells transfected with vector + NC, vector+ miR-25 and KLF4 + miR-25. Transfected (C) Calu1 and (D) A549 cells were used in would healing assays. Transfected (E) Calu1 and (F) A549 cells were used in migration and invasion assays. ${ }^{*} \mathrm{P}<0.05,{ }^{* *} \mathrm{P}<0.01$ and ${ }^{* * * *} \mathrm{P}<0.001$. NC, mimic negative control; miR, microRNA; KLF4, Krüppel-like factor 4. 


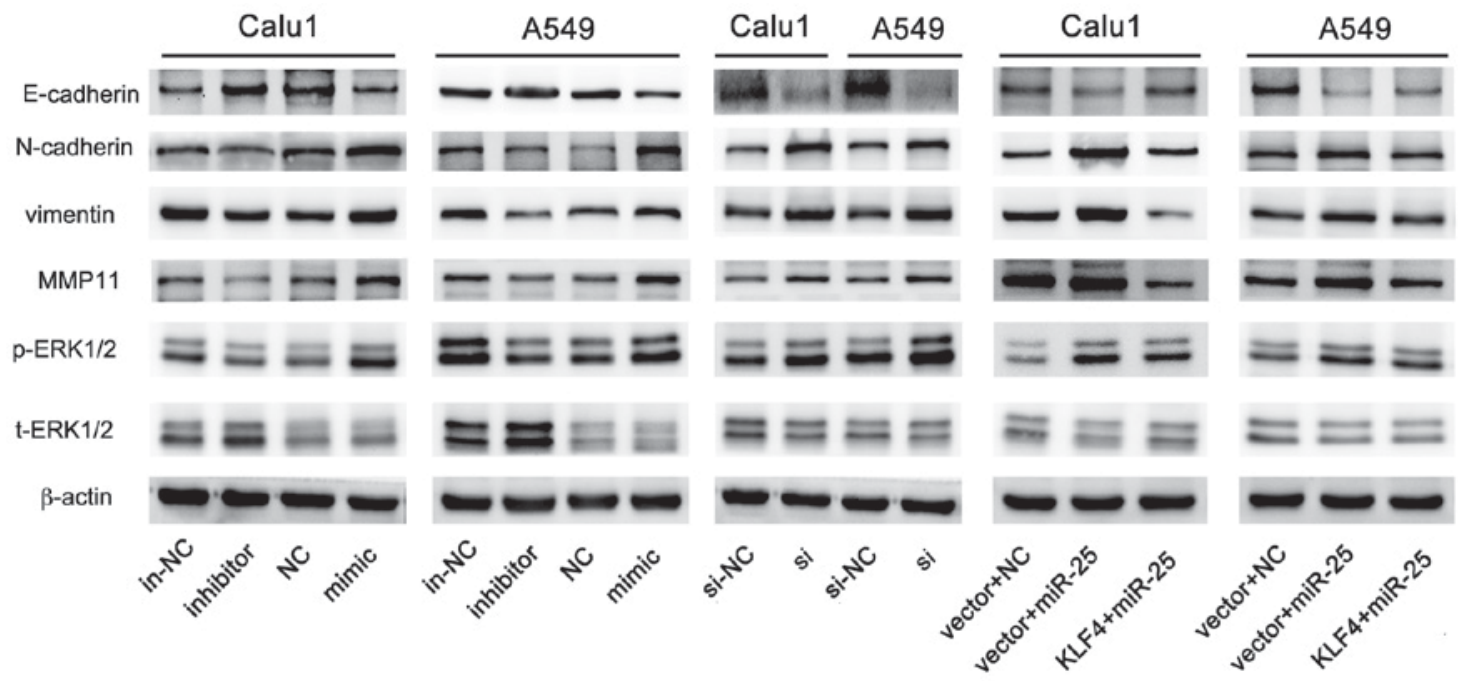

Figure 9. miR-25 promotes cells invasion and migration via the ERK signaling pathway. The expression of E-cadherin, N-cadherin, vimentin, MMP11, p-ERK1/2, t-ERK1/2 and $\beta$-actin in A549 and Calu1 post-transfection with miR-25 inhibitor, miR-25 mimic, KLF4 si or KLF4 + miR-25. MMP11, matrix metalloproteinase; p-, phospho-; ERK, extracellular signal-regulated kinase; t-, total-; in-NC, inhibitor negative control; NC, mimic negative control; si-NC, si negative control; si, KLF4 small interfering RNA; miR, microRNA; KLF4, Krüppel-like factor 4.

promoted cell invasion and migration, similar to the effects of miR-25 overexpression; However, overexpressing KLF4 induced the opposite effects.

Providing that the restoration of KLF4 partly reversed the effect of miR-25 on inhibiting lung cancer cell invasion and migration, the present study aimed to identify the downstream cascade effectors. Based on previous work, particular attention given to ERK1/2, a promoter of cell invasion progression. Zheng et al (39) demonstrated that KLF4 was involved in antiproliferative functions in vascular smooth muscle cells in culture, and knockdown of KLF4 slightly increased p-ERK1/2 levels. Thus, the present study aimed to verify whether miR-25 regulated the ERK signaling pathway by altering the expression of KLF4. Markers of invasion (MMP11, vimentin) and epithelial-to-mesenchymal transition (E- and N-cadherin) were detected at the protein level. The results of the present study demonstrated that the downregulation of KLF4 activated the ERK signaling pathway, increasing the expression of $\mathrm{N}$-cadherin, MMP11 and vimentin, with reduced E-cadherin expression.

Currently, few reports have investigated the downstream signaling pathway of miR-25, or the association between miR-25 and ERK signaling. Additionally, few studies have assessed the expression of miR-25 and KLF4 in clinical samples. The limited number of clinical sample abundance and lack of further research regarding how KLF4 affects the ERK pathway were limitations of the present study.

In summary, miR-25 was significantly overexpressed in NSCLC tissues compared with paracancerous tissue in the present study, and the exogenous addition of miR-25 significantly promoted cell motility of NSCLC cells by reducing the expression of KLF4. In addition, miR-25 was observed to induce migration and invasion of NSCLC cells by regulating the ERK signaling pathway, particularly by affecting the phosphorylation status of molecules upstream of ERK1/2. The results of the present study indicated that miR-25 may be a potential therapeutic target for future NSCLC treatment.

\section{References}

1. Torre LA, Bray F, Siegel RL, Ferlay J, Lortet-Tieulent J and Jemal A: Global cancer statistics, 2012. CA Cancer J Clin 65: 87-108, 2015.

2. Torre LA, Siegel RL and Jemal A: Lung cancer statistics. Adv Exp Med Biol 893: 1-19, 2016.

3. Chen Z, Fillmore CM, Hammerman PS, Kim CF and Wong KK: Non-small-cell lung cancers: A heterogeneous set of diseases. Nat Rev Cancer 14: 535-546, 2014.

4. Moreira AL and Eng J: Personalized therapy for lung cancer. Chest 146: 1649-1657, 2014.

5. Preiss A, Rosenberg UB, Kienlin A, Seifert E and Jäckle H: Molecular genetics of Kruppel, a gene required for segmentation of the drosophila embryo. Nature 313: 27-32, 1985.

6. Shields JM, Christy RJ and Yang VW: Identification and characterization of a gene encoding a gut-enriched Kruppel-like factor expressed during growth arrest. J Biol Chem 271: 20009-20017, 1996.

7. Pandya AY, Talley LI, Frost AR, Fitzgerald TJ, Trivedi V, Chakravarthy M, Chhieng DC, Grizzle WE, Engler JA, Krontiras H, et al: Nuclear localization of KLF4 is associated with an aggressive phenotype in early-stage breast cancer. Clin Cancer Res 10: 2709-2719, 2004.

8. Chen YJ, Wu CY, Chang CC, Ma CJ, Li MC and Chen CM: Nuclear Kruppel-like factor 4 expression is associated with human skin squamous cell carcinoma progression and metastasis. Cancer Biol Ther 7: 777-782, 2008.

9. Wang N, Liu ZH, Ding F, Wang XQ, Zhou CN and Wu M: Down-regulation of gut-enriched Kruppel-like factor expression in esophageal cancer. World J Gastroenterol 8: 966-970, 2002.

10. Wei D, Gong W, Kanai M, Schlunk C, Wang L, Yao JC, Wu TT, Huang S and Xie K: Drastic down-regulation of Kruppel-like factor 4 expression is critical in human gastric cancer development and progression. Cancer Res 65: 2746-2754, 2005.

11. Wei D, Kanai M, Huang S and Xie K: Emerging role of KLF4 in human gastrointestinal cancer. Carcinogenesis 27: 23-31, 2006.

12. Bartel DP: MicroRNAs: Genomics, biogenesis, mechanism, and function. Cell 116: 281-297, 2004.

13. Friedman RC, Farh KK, Burge CB and Bartel DP: Most mammalian mRNAs are conserved targets of microRNAs. Genome Res 19: 92-105, 2009.

14. Li X, Li H, Zhang R, Liu J and Liu J: MicroRNA-449a inhibits proliferation and induces apoptosis by directly repressing E2F3 in gastric cancer. Cell Physiol Biochem 35: 2033-2042, 2015.

15. Yang C, Ning S, Li Z, Qin X and Xu W: miR-22 is down-regulated in esophageal squamous cell carcinoma and inhibits cell migration and invasion. Cancer Cell Int 14: 138, 2014. 
16. Wang D, Qiu C, Zhang H, Wang J, Cui Q and Yin Y: Human microRNA oncogenes and tumor suppressors show significantly different biological patterns: From functions to targets. PLoS One 5: pii: e13067, 2010.

17. Xiao P, Liu W and Zhou H: miR-429 promotes the proliferation of non-small cell lung cancer cells via targeting DLC-1. Oncol Lett 12: 2163-2168, 2016.

18. Hu W, Jin P, Ding C and Liu W: miR-19a/b modulates lung cancer cells metastasis through suppression of MXD1 expression. Oncol Lett 12: 1901-1905, 2016

19. Wang WM andLiu JC: Effect and molecular mechanism of mir-146a on proliferation of lung cancer cells by targeting and regulating MIF gene. Asian Pac J Trop Med 9: 806-811, 2016.

20. Zhang HB, Sun LC, Ling L, Cong LH and Lian R: miR-143 suppresses the proliferation of NSCLC cells by inhibiting the epidermal growth factor receptor. Exp Ther Med 12: 1795-1802, 2016.

21. Shi H, Ji Y,Zhang D, Liu Y and Fang P: MicroRNA-3666-induced suppression of SIRT7 inhibits the growth of non-small cell lung cancer cells. Oncol Rep 36: 3051-3057, 2016.

22. Perepelyuk M, Maher C, Lakshmikuttyamma A and Shoyele SA: Aptamer-hybrid nanoparticle bioconjugate efficiently delivers miRNA-29b to non-small-cell lung cancer cells and inhibits growth by downregulating essential oncoproteins. Int J Nanomedicine 11: 3533-3544, 2016.

23. Petrocca F, Vecchione A and Croce CM: Emerging role of miR-106b-25/miR-17-92 clusters in the control of transforming growth factor beta signaling. Cancer Res 68: 8191-8194, 2008.

24. Savita U and Karunagaran D: MicroRNA-106b-25 cluster targets $\beta$-TRCP2, increases the expression of Snail and enhances cell migration and invasion in H1299 (non small cell lung cancer) cells. Biochem Biophys Res Commun 434: 841-847, 2013.

25. Su ZX, Zhao J, Rong ZH, Geng WM, Wu YG and Qin CK: Upregulation of microRNA-25 associates with prognosis in hepatocellular carcinoma. Diagn Pathol 9: 47, 2014.

26. Li BS, Zuo QF, Zhao YL, Xiao B, Zhuang Y, Mao XH, Wu C, Yang SM, Zeng H, Zou QM and Guo G: MicroRNA-25 promotes gastric cancer migration, invasion and proliferation by directly targeting transducer of ERBB2, 1 and correlates with poor survival. Oncogene 34: 2556-2565, 2015.

27. Zhou J, Wang J, Wu S, Zhu S, Wang S, Zhou H, Tian X, Tang N and Nie S: Angiopoietin-like protein 2 negatively regulated by microRNA-25 contributes to the malignant progression of colorectal cancer. Int J Mol Med 34: 1286-1292, 2014.

28. Wu T, Chen W, Kong D, Li X, Lu H, Liu S, Wang J, Du L, Kong Q, Huang $\mathrm{X}$ and $\mathrm{Lu} \mathrm{Z}$ : miR-25 targets the modulator of apoptosis 1 gene in lung cancer. Carcinogenesis 36: 925-935, 2015.

29. Xiang J, Hang JB, Che JM and Li HC: MiR-25 is up-regulated in non-small cell lung cancer and promotes cell proliferation and motility by targeting FBXW7. Int J Clin Exp Pathol 8: 9147-9153, 2015.
30. Livak KJ and Schmittgen TD: Analysis of relative gene expression data using real-time quantitative PCR and the 2(-Delta Delta C(T)) method. Methods 25: 402-408, 2001

31. Wang Z, Wang J, Yang Y, Hao B, Wang R, Li Y and Wu Q: Loss of has-miR-337-3p expression is associated with lymph node metastasis of human gastric cancer. J Exp Clin Cancer Res 32: 76, 2013.

32. Chen X, Zhai Y, Yu D, Cui J, Hu JF and Li W: Valproic acid enhances iPSC induction from human bone marrow-derived cells through the suppression of reprogramming-induced senescence. J Cell Physiol 231: 1719-1727, 2016.

33. Zhai Y, Chen X, Yu D, Li T, Cui J, Wang G, Hu JF and Li W: Histone deacetylase inhibitor valproic acid promotes the induction of pluripotency in mouse fibroblasts by suppressing reprogramming-induced senescence stress. Exp Cell Res 337: 61-67, 2015.

34. Patel RS, Carter G, El Bassit G, Patel AA, Cooper DR, Murr M and Patel NA: Adipose-derived stem cells from lean and obese humans show depot specific differences in their stem cell markers, exosome contents and senescence: Role of protein kinase $\mathrm{C}$ delta $(\mathrm{PKC} \delta)$ in adipose stem cell niche. Stem Cell Investig 3: 2, 2016.

35. Xu Q, Liu M, Zhang J, Xue L, Zhang G, Hu C, Wang Z, He S, Chen L, Ma K, et al: Overexpression of KLF4 promotes cell senescence through microRNA-203-survivin-p21 pathway. Oncotarget 7: 60290-60302, 2016

36. Yu T, Chen X, Zhang W, Liu J, Avdiushko R, Napier DL, Liu AX, Neltner JM, Wang C, Cohen D and Liu C: KLF4 regulates adult lung tumor-initiating cells and represses K-Ras-mediated lung cancer. Cell Death Differ 23: 207-215, 2016.

37. Hu W, Jia Y, Xiao X, Lv K, Chen Y, Wang L, Luo X, Liu T, Li W, Li Y, et al: KLF4 downregulates hTERT expression and telomerase activity to inhibit lung carcinoma growth. Oncotarget 7: 52870-52887, 2016.

38. Hu W, Hofstetter WL, Li H, Zhou Y, He Y, Pataer A, Wang L, Xie K, Swisher SG and Fang B: Putative tumor-suppressive function of Kruppel-like factor 4 in primary lung carcinoma. Clin Cancer Res 15: 5688-5695, 2009.

39. Zheng B, Han M, Bernier M, Zhang XH, Meng F, Miao SB, He M, Zhao XM and Wen JK: Kruppel-like factor 4 inhibits proliferation by platelet-derived growth factor receptor beta-mediated, not by retinoic acid receptor alpha-mediated, phosphatidylinositol 3-kinase and ERK signaling in vascular smooth muscle cells. J Biol Chem 284: 22773-22785, 2009.

This work is licensed under a Creative Commons Attribution-NonCommercial-NoDerivatives 4.0 International (CC BY-NC-ND 4.0) License. 